\title{
Planejamento físico-funcional: Subsídio para a segurança dos alimentos na produção de refeições
}

\author{
Physical-functional planning: Subsidy for food safety in meal production \\ Planificación físico-funcional: Subvención a la seguridad alimentaria en la producción de comidas
}

Recebido: 10/02/2022 | Revisado: 19/02/2022 | Aceito: 21/02/2022 | Publicado: 03/03/2022

\author{
Beatriz Castro Fernandes \\ ORCID: https://orcid.org/0000-0002-9015-9087 \\ Universidade Federal da Bahia, Brasil \\ E-mail: beatriz.cfe@gmail.com \\ Carlos Rodrigo Nascimento de Lira \\ ORCID: https://orcid.org/0000-0001-7266-1367 \\ Universidade Federal da Bahia, Brasil \\ E-mail: carlos.rodrigo.n@hotmail.com \\ Jeane dos Santos Ferreira \\ ORCID: https://orcid.org/0000-0002-3768-9417 \\ Universidade Federal da Bahia, Brasil \\ E-mail: jeane.nut@hotmail.com \\ Maria da Conceição Pereira da Fonseca \\ ORCID: https://orcid.org/0000-0003-0325-7162 \\ Universidade Federal da Bahia, Brasil \\ E-mail:mcfonseca@gmail.com
}

\begin{abstract}
Resumo
Objetivos: Avaliar a estrutura física de um restaurante universitário de acordo com os critérios para Boas Práticas de Fabricação, analisar o dimensionamento dos setores, o fluxo de produção e sugerir novo layout. Métodos: Trata-se de um estudo com delineamento descritivo, realizado em um Restaurante Universitário em Salvador, Bahia. A pesquisa foi realizada em três etapas: I - aplicação da lista de verificação para análise das Boas Práticas de Fabricação; II avaliou-se o dimensionamento físico da Unidade de acordo com a literatura, e do fluxo de produção através da planta baixa; III - sugestão de novo dimensionamento e fluxo de produção. Resultados: A Unidade obteve 65,03\% (Grupo 2) de adequação à legislação sanitária. O dimensionamento dos setores da Unidade apresentou redução de, em média, $42,13 \%$ em relação ao recomendado pela literatura consultada. O novo layout proposto aproveitou melhor os espaços e ampliou a área de produção em $102,18 \mathrm{~m}^{2}$ mesmo sem exceder o espaço já disponível pela Instituição, além de solucionar o problema dos cruzamentos de fluxo. Conclusão: A Unidade apresentou diversas inadequações em relação à legislação e aos quesitos de Boas Práticas de Fabricação e apresentou dimensionamento físico subdimensionado. Estes fatores contribuem para o aumento do risco de contaminação cruzada que pode favorecer a ocorrência de doenças veiculadas por alimentos.
\end{abstract}

Palavras-chave: Dimensionamento; Planejamento físico; Boas práticas de fabricação; Design baseado em evidências.

\begin{abstract}
Objectives: Evaluate the physical structure of a university restaurant according to the criteria for Good Manufacturing Practices, analyze the dimension of the sectors, the production flow and suggest a new layout. Methods: This is a study with descriptive design, carried out in a University Restaurant in Salvador, Bahia. The research was carried out in three stages: I - application of the checklist for the analysis of Good Manufacturing Practices; II - the physical dimensioning of the Unit was evaluated according to the literature, and the production flow through the floor plan; III - suggestion of new sizing and production flow. Results: The Unit obtained $65.03 \%$ (Group 2) of compliance with health legislation. The dimensioning of the Unit's sectors presented a reduction of, on average, $42.13 \%$ in relation to what is recommended in the consulted literature. The new proposed layout made better use of the spaces and expanded the production area by $102.18 \mathrm{~m}^{2}$ even without exceeding the space already available by the Institution, in addition to solving the problem of flow crossings. Conclusion: The Unit presented several inadequacies in relation to legislation and the requirements of Good Manufacturing Practices and undersized physical sizing presentation. These factors contribute to the increased risk of cross-contamination that can favor the occurrence of foodborne illnesses.
\end{abstract}

Keywords: Sizing; physical planning; Good manufacturing practices; Evidence-based facility design.

\section{Resumen}

Objetivos: Evaluar la estructura física de un restaurante universitario según los criterios de Buenas Prácticas de Manufactura, analizar la dimensión de los sectores, el flujo de producción y proponer una nueva distribución. 
Métodos: Se trata de un estudio con diseño descriptivo, realizado en un Restaurante Universitario de Salvador, Bahía. La investigación se llevó a cabo en tres etapas: I - aplicación del checklist para el análisis de Buenas Prácticas de Manufactura; II - se evaluó el dimensionamiento físico de la Unidad de acuerdo a la literatura, y el flujo de producción a través del plano de planta; III - sugerencia de nuevo dimensionamiento y flujo de producción. Resultados: La Unidad obtuvo 65,03\% (Grupo 2) de cumplimiento de la legislación sanitaria. El dimensionamiento de los sectores de la Unidad presentó una reducción de, en promedio, $42,13 \%$ en relación a lo recomendado en la literatura consultada. La nueva distribución propuesta hizo un mejor aprovechamiento de los espacios y amplió el área de producción en $102,18 \mathrm{~m}^{2}$ incluso sin exceder el espacio ya disponible por la Institución, además de solucionar el problema de los cruces de flujo. Conclusión: La Unidad presentó varias deficiencias en relación a la legislación y los requisitos de Buenas Prácticas de Manufactura y presentación de tamaño físico de tamaño insuficiente. Estos factores contribuyen al aumento del riesgo de contaminación cruzada que puede favorecer la aparición de enfermedades transmitidas por los alimentos.

Palabras clave: Dimensionamiento; Planificación física; Buenas prácticas de fabricación; Diseño de instalaciones basado en evidencias.

\section{Introdução}

A produção de refeições implica em exposição ao contato com microrganismos que podem ser patogênicos ou deterioradores (Franco \& Landgraf, 2003). Entretanto, corretas medidas de controle da produção resultam na redução da contaminação dos alimentos, garantindo assim a qualidade do produto final (Silva Junior, 2014).

A construção de uma Unidade de Alimentação e Nutrição (UAN), com base em um adequado planejamento físicofuncional, tem como objetivo atender às recomendações higienicossanitárias a fim de evitar a contaminação e prevenir a ocorrência de doenças veiculadas por alimentos ${ }^{3}$. Assim, pode-se então afirmar que a segurança da produção de refeições se inicia com o planejamento do layout da planta de processamento (Correia \& Rocha, 2012; Sant'Ana, 2012), e um planejamento feito a posteriori pode incorrer em tempos de processamento excessivamente longos, operações inflexíveis, fluxos inadequados e perda do controle de higiene e segurança dos alimentos (Silva \& Rentes, 2012).

Os estudos sobre estrutura física, layout e fluxo de produção, apesar de incipientes, são extremamente importantes, pois tem direta relação com a garantia da qualidade higienicossanitária da produção de refeições. A participação do Nutricionista na equipe multidisciplinar responsável pelo projeto é indispensável, pois é o profissional que melhor compreende as necessidades deste ambiente e conhece a realidade da produção de refeições (Conselho Federal de Nutricionistas, 2018).

Diante do exposto, o presente estudo teve por objetivo avaliar a estrutura física de uma Unidade de Alimentação e Nutrição de acordo com os critérios para as Boas Práticas de Fabricação (BPF), bem como analisar o dimensionamento dos setores, o fluxo de produção e sugerir um novo layout, a partir das inadequações identificadas.

\section{Metodologia}

Trata-se de um estudo descritivo (Köche, 2011), realizado em um Restaurante Universitário (RU) em Salvador, Bahia. A Unidade foi escolhida por conveniência e a coleta dos dados ocorreu entre abril e agosto de 2015. O estudo faz parte de um projeto maior, aprovado pelo Comitê de Ética em Pesquisa da Escola de Nutrição da Universidade Federal da Bahia $\left(\mathrm{n}^{0} 228.318 / 2012\right)$.

A pesquisa foi realizada em quatro etapas. Primeiramente uma caracterização da UAN foi realizada (identificação do tipo de serviço prestado, padrão de cardápio, número de refeições produzidas e número de comensais). Em segundo lugar, para analisar as Boas Práticas de Fabricação na UAN, de acordo com a legislação sanitária vigente, utilizou-se a lista de verificação das boas práticas de fabricação em estabelecimentos produtores/industrializadores de alimentos, presente no Anexo II da Resolução da Diretoria Colegiada - RDC n²75 da Agência Nacional de Vigilância Sanitária - ANVISA (Brasil, 2002).

A escolha desta lista de verificação se deu por sua aplicação em todo território nacional, facilitando a comparação dos achados e principalmente por seu nível de detalhamento nos quesitos que envolvem estrutura física, além de avaliação sobre os 
equipamentos, móveis e utensílios; manipuladores; produção e transporte; e a documentação do estabelecimento, sendo então o instrumento mais amplo e adequado para o estudo.

Após aplicação do instrumento, a UAN foi classificada em grupos, de acordo com o percentual de adequação: a) Grupo 1 - entre 76 e 100\% de adequação, que classifica a Unidade como adequada à produção segura de refeições; b) Grupo 2 - entre 51 e 75\% de adequação, ou seja, a Unidade é segura, porém com necessidade de melhorias para maior adequação à produção de refeições; c) Grupo 3 - entre 0 e 50\% de adequação e a Unidade é considera como não estando em condições adequadas à produção segura de refeições.

$\mathrm{Na}$ terceira etapa, para a avaliação do dimensionamento físico e fluxo de produção, os dados foram obtidos através da planta baixa e posteriormente avaliou-se a adequação deste dimensionamento de acordo com a literatura, utilizando como referências os métodos propostos por Sant'Ana (2012) e Silva Filho (1996).

Foi considerada a média aritmética dos índices sugeridos por Sant’Ana (2012), já que o cardápio da Unidade em estudo tratava-se de padrão médio. Os índices apresentados por esta referência são diretamente aplicáveis a UAN com total de 2.000 e 2.500 refeições, sendo que para cada redução de 200 refeições em relação a 2.000 refeições, deve-se acrescentar $10 \%$ na área calculada. Neste caso, o total de refeições da UAN em estudo, 1.420, representou 2,9 reduções de 200 refeições e, portanto as áreas foram aumentadas em $29 \%$ em relação ao calculado.

Já para Silva Filho (1996) foi considerado o índice 0,28, pois é o utilizado para 1.500 refeições, que é o valor mais próximo do valor real servido na UAN.

As análises acerca dos percentuais de adequação entre os valores sugeridos e o dimensionamento existente foram feitas através do Microsoft Excelß versão 2010. O percentual apresenta-se negativo quando a área existente é subdimensionada e positivo quando a área existente é adequada ou superdimensionada. O layout e o fluxo de produção foram analisados a partir da planta baixa e da observação direta das atividades realizadas no local.

Por fim, buscando adequar a UAN aos critérios de BPF foi sugerido um novo dimensionamento e disposição das áreas. A nova proposta foi feita com base no espaço físico e recursos disponíveis pela Instituição, utilizando o programa Autocad® versão 18.1.

Para adequar o número de refeições a serem produzidas ao novo projeto, foi utilizada a referência adaptada de Teixeira et al. (1992) citada por Sant'Ana (2012), considerando o índice para área total e o índice total excluindo o salão de refeições mais próximo do número de refeições servidas no momento do estudo, ou seja, utilizou-se o índice para 1.000 refeições. Posteriormente foi realizada regra de três para calcular o número de refeições que podem ser produzidas de forma segura na área projetada para ambos os índices e então foi feita uma média aritmética entre estes valores para se chegar à capacidade máxima de atendimento do novo projeto.

\section{Resultados e Discussão}

\section{Caracterização da Unidade}

A gestão da UAN era terceirizada, ou seja, uma empresa especializada foi contratada através de licitação e atuava produzindo e distribuindo as refeições sob um sistema de comodato, no qual a mesma utilizava as instalações da contratante para prestação dos serviços. O tipo de contrato estabelecido era o de "preço fixo", caracterizado pela fixação de um valor unitário para as refeições e todos os custos e riscos eram assumidos pela contratada (Teixeira et al., 1990).

A UAN distribuía três refeições ao dia (desjejum, almoço e jantar) sendo uma parte com distribuição no local em que era produzida e outra parte transportada para a residência universitária. Eram produzidas e distribuídas para a residência universitária 457 refeições, das quais 87 eram o desjejum, 220 almoços e 150 jantares. Para a distribuição no RU, eram produzidas 1.200 e 1.000 refeições para almoço e jantar, respectivamente. O número total de refeições produzidas em um 
mesmo turno era de 1.420 refeições.

O cardápio proposto classificava-se como de padrão médio, sendo composto por duas saladas cruas, prato principal (representando 70\%), opção ovolactovegetariana (representando 30\% das refeições), guarnição, sobremesa (frutas ou doces), acompanhamentos (arroz e feijão) e bebida não alcoólica. O perfil dos comensais era diversificado, sendo constituída em sua maioria por estudantes universitários (pagantes e bolsistas), funcionários técnicos servidores e docentes.

\section{Lista de Verificação}

A UAN obteve $65,03 \%$ de atendimento aos itens da lista de verificação, classificando-se no Grupo 2 e apresentou diversos aspectos inadequados em relação à legislação vigente (Brasil, 2002). Quando avaliada a adequação por blocos da lista de verificação, observou-se que o bloco com maior percentual de adequação foi o de "Manipuladores", seguido pelos blocos "Documentação" e "Equipamentos, móveis e utensílios". Já o bloco com maior percentual de inadequação foi o referente à "Produção e transporte", seguido pelo bloco "Edificações e instalações", sendo este resultado inferior ao relatado por estudos (Bernardo et al., 2014; Ferreira et al., 2011; São José et al., 2011) conduzidos em UAN de pequeno e médio porte, os quais obtiveram porcentagens de adequação acima de 75\% para este bloco (Figura 1). Em contrapartida, no estudo de Susin et al. (2017) os blocos condições das instalações, organização e limpeza da cozinha, documentações e legislação e instalações e edificações foram os blocos que apresentaram menores pontuações de adequação.

Figura 1 - Percentual de adequação e inadequação da lista de verificação por blocos no Restaurante Universitário em estudo. Salvador, Bahia, 2015.

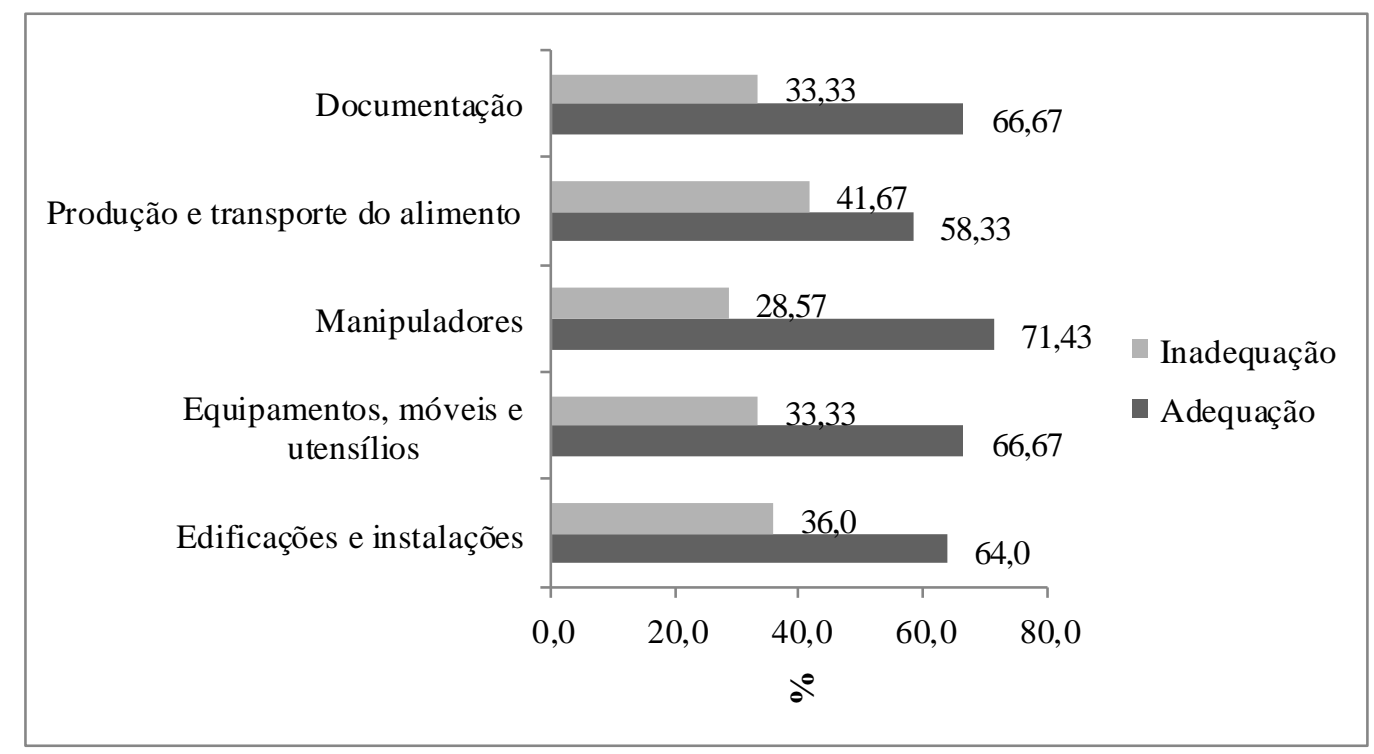

Fonte: Autores.

Ao que se refere o bloco "Edificações e instalações", a localização da UAN foi um dos quesitos que se apresentou fora dos padrões exigidos pela legislação, pois a mesma localizava-se em meio à vegetação que abrigava animais e vetores, facilitando a entrada destes na área de produção. Além disso, foram observados objetos em desuso na área. Segundo a RDC n²16 (Brasil, 2004), unidades de alimentação e nutrição devem estar situadas em locais livres de focos de insalubridade, água estagnada e sem presença de animais e vetores, divergindo, portanto, dos achados deste estudo.

Também foram encontradas inadequações referentes ao estado de conservação da área, envolvendo fatores como pisos com rachaduras na área de preparo e teto do sanitário feminino das manipuladoras com falhas e goteiras. A inexistência de ângulos abaulados entre as paredes e o teto e as portas sem acionamento automático e sem proteção contra vetores também 
foram inadequações encontradas. Além disso, as portas estavam em péssimo estado de conservação, ausência de porta para separar a área de lavagem de panelas da área de cocção, gerando risco de contaminação dos alimentos por contato com os resíduos dos produtos de limpeza. Outra inadequação encontrada foi ausência de lavatórios para lavagem das mãos em número suficiente na área de produção e sem acionamento automático.

Ao avaliarem as condições ambientais em dois restaurantes universitários de Pelotas - RS, Leal et al. (2019) encontraram como maiores inadequações as condições dos pisos e ralos (33,34\%), paredes e teto (50\%), portas e janelas (50\%), iluminação e instalações elétricas $(66,67 \%)$. A adequação das edificações contribui para a adoção das BPF dado a facilitação dos processos de limpeza e higienização, além de possibilitar um fluxo de produção seguro (Brasil, 2004; Cardoso et al., 2010; Sant'Ana, 2012). O Codex Alimentarius (1993) prevê que as instalações de UAN devem evitar a ocorrência de contaminações cruzadas, consideradas a principal causa de doenças veiculadas por alimentos.

No bloco "Equipamentos, móveis e utensílios", as principais inadequações encontradas foram relacionadas ao estado de conservação dos equipamentos e móveis da Unidade, que apresentavam corrosão ou estavam quebrados. Além disso, o número de equipamentos e móveis mostrou-se insuficiente para atender à demanda e não existiam registros dos procedimentos de higienização dos equipamentos, assim como encontrado no estudo de São José, Coelho \& Ferreira (2011). O número insuficiente de equipamentos e móveis faz com que a produção se torne menos eficiente e favoreça a contaminação cruzada, pois há menos espaços para o pré-preparo e as bancadas passam a ser compartilhadas entre diversas atividades. Equipamentos e utensílios que entram em contato direto com alimentos devem estar em condições ideais, ter desenho adequado à produção, serem impermeáveis e resistentes à corrosão e estarem em adequado estado de conservação e limpeza para não representarem perigo à produção de refeições seguras (Brasil, 2004).

Quanto aos manipuladores de alimentos, foram observadas inadequações neste bloco em relação às práticas dos mesmos, como a não utilização dos Equipamentos de Proteção Individual (EPI), tais como máscaras e casacos térmicos. Neste caso, os manipuladores justificavam que os mesmos eram incômodos ao usá-los. Bernardo et al. (2014) também encontraram negligência no uso de EPI, além da inexistência de alguns deles na Unidade. Também, foram observadas inadequações referentes à higienização das mãos neste estudo, tanto no que concerne à frequência quanto à maneira de realizar o procedimento, apesar da existência dos cartazes explicativos.

As práticas de higiene dos manipuladores são de extrema importância para a garantia da segurança na produção de alimentos e o constante treinamento e capacitação é eficaz para torná-los motivados e conhecedores das boas práticas de fabricação (Silva Júnior, 2014). Uma série de treinamentos foi realizado na UAN em estudo, após ocorrência de surto de toxinfecção alimentar, e observou-se que as inadequações na manipulação de alimentos tinham sua origem na ineficiente gestão de pessoas, abrangendo desde o processo de seleção de funcionários até a falta de treinamento e supervisão dos mesmos. Foram observadas importantes mudanças comportamentais em relação ao controle de temperatura, higienização das mãos e maior responsabilidade com relação aos aspectos higiênico-sanitários (Alonso et al., 2015). Tal fato pode ter contribuído para a melhora da qualidade da produção e pode explicar a boa adequação deste bloco neste estudo. Em seu estudo, Bernardo et al. (2014) observaram como principal inadequação neste bloco, a inexistência de cartazes de orientação afixados em locais adequados. São José et al. (2011) também observaram práticas inadequadas de lavagem de mãos.

A falta de inspeção adequada dos produtos durante o recebimento se constituiu como uma falha neste processo no bloco "Produção e transporte", pois eram conferidos apenas os pesos sem a observação acerca da temperatura, condições das embalagens ou características sensoriais dos produtos. As práticas inadequadas na análise qualitativa durante o recebimento da matéria-prima trazem implicações na qualidade final do produto e, do ponto de vista financeiro, aumenta o desperdício, pois parte dos alimentos recebidos podem não se encontrar em condições para uso. Segundo Teixeira et al. (1990) todo o produto a ser recebido em uma UAN deve ser inspecionado qualitativamente, sendo importante a observação de aspectos como as 
características de embalagem, data de fabricação e validade, rotulagem e avaliação sensorial, além de ser necessário verificar tanto o carro, quanto o profissional encarregado da entrega.

$\mathrm{O}$ armazenamento dos alimentos também apresentou inadequações causadas principalmente pela falta de espaço para armazenamento dos gêneros em cadeia fria, principalmente vegetais, que ficavam estocados fora da temperatura adequada e em local inapropriado. $\mathrm{O}$ armazenamento em temperatura controlada de gêneros perecíveis é indispensável e deve ser feita separadamente de acordo com o tipo de material a ser armazenado, sejam produtos in natura, alimentos pré-preparados ou prontos pra consumo. Tal procedimento tem impacto direto na qualidade e segurança do produto final e reduz o risco de contaminações e ocorrência de doenças veiculadas por alimentos (Brasil, 2004; Sant’Ana, 2012; Silva \& Rentes, 2012).

O bloco referente à "Documentação" avalia a existência e aplicação do Manual de Boas Práticas de Fabricação e dos Procedimentos Operacionais Padrão (POP). As inconformidades encontradas neste bloco foram referentes ao descumprimento dos POP existentes no Manual de Boas Práticas. Não estavam sendo cumpridos os POP referentes à higienização das instalações, equipamentos e utensílios, já que não havia registro dessa atividade e por vezes as condições das instalações estavam precárias; à higiene e saúde dos manipuladores, pois as operações de lavagem de mãos eram negligenciadas, já que não foram observadas tais práticas por todos os manipuladores, constituindo-se como um desvio no cumprimento de tal procedimento; e ao controle integrado de vetores e pragas urbanas, pois eram observados vetores na UAN.

Ferreira et al. (2011), em estudo conduzido em seis (6) hotéis de Belo Horizonte, encontraram que o bloco "Documentação" obteve maior porcentagem de inadequação, diferentemente do presente estudo. Segundo a RDC n²16 (Brasil, 2004), o Manual de Boas Práticas e os POP são documentos obrigatórios e imprescindíveis em UAN, pois auxiliam na gestão das atividades produtivas considerando a segurança higiênico-sanitária e a prevenção de perigos que podem ser fontes de contaminação para os alimentos (Bernardo et al., 2014).

\section{Dimensionamento da UAN e sugestão de novo layout}

A Unidade estudada possuía $410,90 \mathrm{~m}^{2}$ de área disponível para a produção de refeições, desde a recepção, armazenamento, pré-preparo, preparo e distribuição. Ao todo eram $1.635,83 \mathrm{~m}^{2}$ de área incluindo o salão de refeições e áreas anexas, de acordo com a planta baixa. Quando comparadas as áreas existentes com as áreas calculadas pelo método proposto por Sant'Ana (2012), as áreas da UAN estavam em média 37,45\% menores do que o recomendado, considerando um máximo de 1.420 refeições produzidas no mesmo turno (Tabela 1).

O método de Sant'Ana (2012) é bastante específico e contempla diversos quesitos importantes de serem analisados quando do cálculo do dimensionamento de setores de UAN, como por exemplo, a capacidade máxima de produção da Unidade por turno, o tipo de cardápio e o sistema de produção. Para a autora, pode ser aceitável uma diferença de até 5\%, acima ou abaixo do calculado. 
Tabela 1 - Comparação entre área atual e área calculada pelo método de Sant'Ana (2012) com respectivo percentual de adequação no Restaurante Universitário. Salvador, Bahia, 2015.

\begin{tabular}{|c|c|c|c|}
\hline Setor & Área atual $\left(\mathrm{m}^{2}\right)$ & Área calculada $\left(\mathrm{m}^{2}\right)$ & $\%$ de adequação \\
\hline Recepção & 50,64 & 33,42 & 51,53 \\
\hline Câmara de laticínios & 5,43 & 16,48 & $-67,05$ \\
\hline Câmara de vegetais & 7,70 & 32,97 & $-76,65$ \\
\hline Câmara de congelados & 8,43 & 16,48 & $-48,85$ \\
\hline Antecâmara & 5,69 & 10,99 & $-48,23$ \\
\hline Despensa & 25,04 & 34,35 & $-27,10$ \\
\hline Pré-preparo de salada & 17,77 & 32,05 & $-44,56$ \\
\hline $\begin{array}{c}\text { Pré-preparo da opção, patissaria } \\
\text { e sobremesa }\end{array}$ & 10,55 & 27,47 & $-61,59$ \\
\hline Açougue & 24,17 & 22,89 & 5,59 \\
\hline Cocção & 59,93 & 128,23 & $-53,26$ \\
\hline Lavagem de panelas & 10,55 & 12,82 & $-17,71$ \\
\hline Lavagem de bandejas & 23,99 & 64,50 & $-62,81$ \\
\hline Distribuição & 60,02 & 140,00 & $-57,13$ \\
\hline Refeitório & 752,42 & 426,00 & 76,62 \\
\hline DML & 1,84 & 4,81 & $-61,75$ \\
\hline Sanitário feminino & 12,88 & 17,41 & $-26,02$ \\
\hline Sanitário masculino & 10,33 & 17,41 & $-40,67$ \\
\hline Vestiário & 11,51 & 96,00 & $-88,01$ \\
\hline Sala do nutricionista & 9,10 & 28,50 & $-68,07$ \\
\hline Administração & 10,67 & 16,00 & $-33,31$ \\
\hline
\end{tabular}

Legenda: DML = depósito de material de limpeza. Fonte: Autoria própria.

Quando o dimensionamento foi avaliado pelo método proposto por Silva Filho (1996) e comparado com a área no momento de realização do estudo, o método apontou que apenas as áreas de armazenamento estavam subdimensionadas (Tabela 2).

O método proposto por Silva Filho (1996) é mais genérico quando comparado ao de Sant'Ana (2012) e aponta algumas divergências, como por exemplo, o fato de resultar em setores superdimensionados com exceção do setor de armazenamento. Além disso, o método não é o mais adequado para ser utilizado na atualidade já que na época do seu desenvolvimento não existiam as mesmas preocupações sobre o controle higiênico-sanitário que existem na atualmente, com a implementação de legislações que introduziram novas necessidades de adequação dos espaços físicos (Brasil, 2002; Brasil, 2004). Além disso, o método divide a Unidade em apenas quatro grandes áreas, calculadas através de porcentagens sobre a área total, e, portanto, acaba por perder a especificidade necessária à análise das necessidades reais de cada setor. 
Tabela 2 - Comparação entre área atual e área calculada pelo método de Silva Filho (1996) com respectivo percentual de adequação no Restaurante Universitário. Salvador, Bahia, 2015.

\begin{tabular}{cccc}
\hline Setor & Área atual $\left(\mathrm{m}^{2}\right)$ & Área calculada $\left(\mathrm{m}^{2}\right)$ & \% de adequação \\
\hline Área total & 410,90 & 397,6 & 3,35 \\
Produção & 173,93 & 159,04 & 9,36 \\
Armazenamento & 60,32 & 79,52 & $-24,14$ \\
Atendimento & 812,44 & 159,04 & 410,84 \\
\hline
\end{tabular}

Fonte: Autoria própria.

A área total do restaurante e o setor de atendimento apareceram com os resultados mais divergentes em relação à área atual, de acordo com Silva Filho (1996), podendo este resultado ser atribuído aos setores de distribuição e refeitório, também apresentados como superestimado por Sant'Ana (2012) e áreas anexas. Já a área de armazenamento foi a única que se apresentou com porcentagem negativa, demonstrando que os espaços estão insuficientes de acordo com o método, corroborando com os resultados encontrados por Sant'Ana (2012).

O dimensionamento adequado de uma UAN, bem como a boa distribuição e alocação dos setores são fatores importantes para a execução de cardápios variados, dentro dos padrões de higiene e qualidade nutricional esperada, e deve ser feito a fim de possibilitar que o fluxo de operações seja realizado dentro de condições higiênicas e seguras (Mezomo, 1994). O estudo sobre as características da UAN, demandas por setores e dimensionamento físico, culmina na elaboração do projeto que deve representar as necessidades específicas da Unidade. A elaboração da planta baixa é uma das etapas mais importantes, pois é nela onde estão representadas a localização e a dimensão dos setores previstos para a UAN e, por consequência, o fluxo de trabalho (Sant'Ana, 2012). Para tal, o planejamento deve ser feito por profissionais que conheçam os processos de trabalho e possam então elencar todos os parâmetros que influenciam no dimensionamento destes locais (Sant'Ana, 2012).

$\mathrm{Na}$ análise dos setores, os de recebimento e refeitório apresentaram dimensões maiores do que as recomendadas por Sant'Ana (2012) e o açougue foi a única área próxima do recomendado. A RDC n⿳216 (Brasil, 2004) sinaliza que o dimensionamento dos setores de uma UAN deve ser compatível com as operações realizadas nos mesmos e Sant'Ana (2012) salienta que áreas maiores do que o necessário resulta em espaços ociosos, que não cumprem a função a que foram destinados, além de exigirem mais deslocamentos de funcionários e onerarem desnecessariamente a construção e montagem da UAN. As demais áreas da UAN apresentaram-se subdimensionadas quando comparadas com as áreas calculadas, sendo os setores com maior déficit de espaço o vestiário dos manipuladores e a câmara de vegetais com dimensões menores do que o recomendado.

A sugestão do novo layout da área do RU em estudo foi baseada principalmente na área já disponível pela Universidade com o objetivo de adequar o fluxo de produção (Figura 2). Como proposta de novo layout, os setores propostos se adequaram às necessidades da Unidade na medida em que permitem a realização das atividades com a devida segurança higiênico-sanitária. O projeto não altera todas as estruturas já existentes e aproveita ao máximo a edificação para promover redução de custos, que é um importante fator para que o planejamento possa ser cumprido. O número de refeições deve ser diminuído para que seja o mais seguro possível, porém observa-se que é uma redução pequena e, portanto, com possibilidade de melhor uso da área disponível pela Instituição e que os espaços estavam, na verdade, mal aproveitados. 
Research, Society and Development, v. 11, n. 3, e46111326844, 2022

(CC BY 4.0) | ISSN 2525-3409 | DOI: http://dx.doi.org/10.33448/rsd-v11i3.26844

Figura 2 - Planta baixa do projeto de novo layout do Restaurante Universitário em estudo. Salvador, Bahia, 2015.

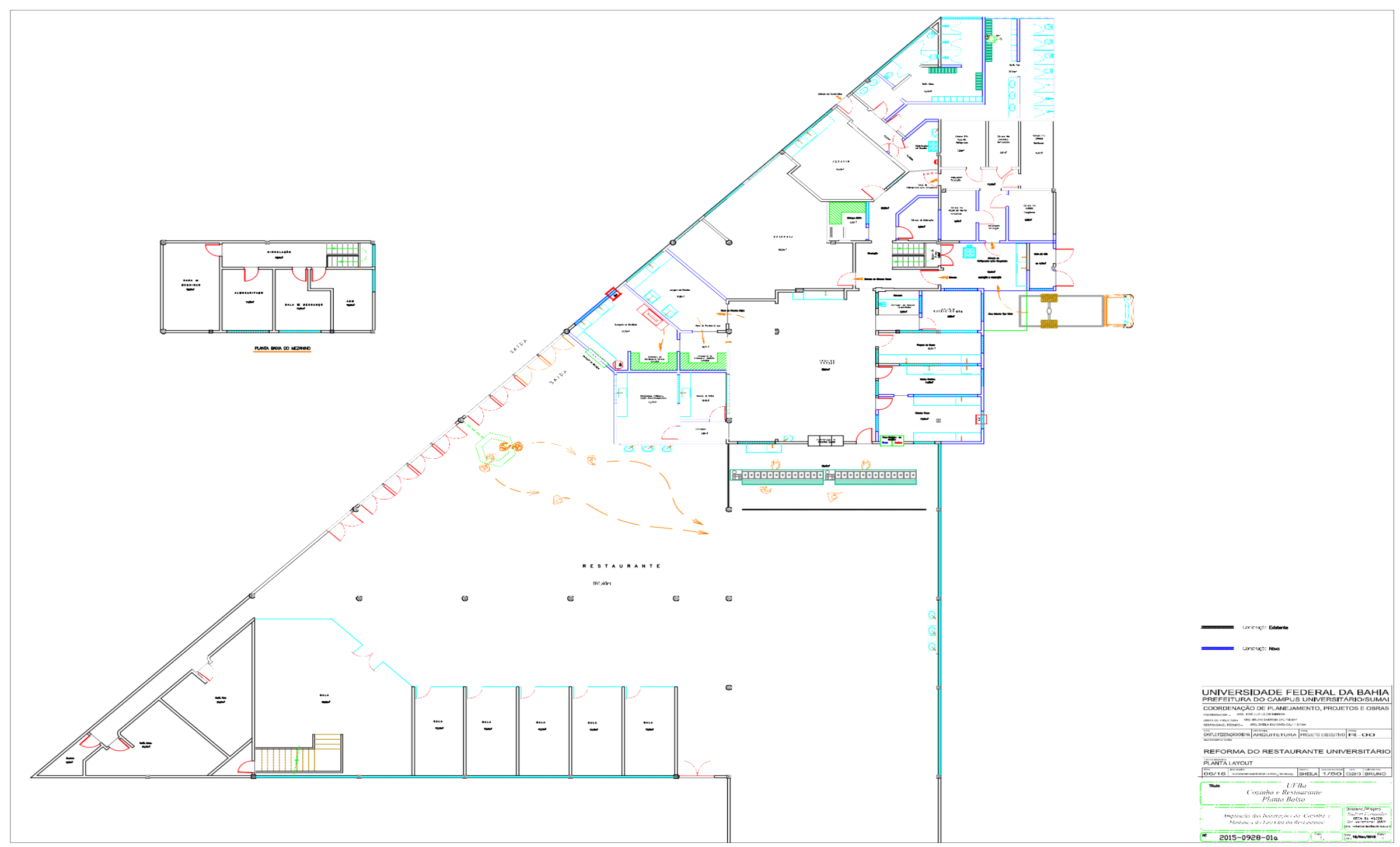

Observação: Para melhor visualização dos setores, aproxime ao máximo o documento $p d f$. Fonte: Autoria própria. 
A localização dos setores de uma UAN deve ser planejada de acordo com critérios técnicos, estando sempre alinhada com a realidade do processo produtivo a fim de respeitar o fluxo linear dos alimentos, desde o recebimento, passando pelo prépreparo, preparo até a distribuição, além do fluxo dos manipuladores, resíduos e comensais. Portanto, as edificações devem ser projetadas a fim de garantir um fluxo ordenado, sem cruzamentos e facilitar as operações de manutenção, limpeza e desinfecção (Brasil, 2004; Sant'Ana, 2012; Silva Júnior, 2014).

Os setores foram ampliados em relação à área disponível (Tabela 3). Tal ampliação não permitiu a adequação dos espaços de acordo com Sant'Ana (2012), mas, de acordo com Teixeira et al. (1992) o número de refeições que poderiam ser produzidas de forma segura de acordo com a área do novo projeto era de 1.693 refeições, o que representa um aumento de 273 refeições.

Tabela 3 - Comparação entre a área atual e a área projetada, com respectivo percentual de adequação, para o Restaurante Universitário em estudo. Salvador, Bahia, 2015.

\begin{tabular}{cccc}
\hline Setor & Área atual $\left(\mathrm{m}^{2}\right)$ & Área projetada $\left(\mathrm{m}^{2}\right)$ & $\%$ de adequação \\
\hline Recepção & 27,79 & 15,49 & 79,41 \\
Câmaras de congelados & 8,43 & 10,78 & $-21,80$ \\
Câmaras refrigeradas & 13,13 & 21,54 & $-39,04$ \\
Antecâmara & 5,69 & 11,10 & $-48,74$ \\
Despensa & 25,04 & 60,03 & $-58,29$ \\
Pré-preparo de salada & 17,77 & 29,19 & $-39,12$ \\
Pré-preparo da opção, patissaria e & 10,55 & 16,17 & $-34,76$ \\
sobremesas & 24,17 & 24,17 & 0,00 \\
Açougue & 7,2 & 12,23 & $-41,13$ \\
Sucos & 59,93 & 83,21 & $-27,98$ \\
Cocção & 23,99 & 22,57 & 6,29 \\
Lavagem de bandejas & 10,55 & 17,61 & $-40,09$ \\
Lavagem de panelas & 3,63 & 4,16 & $-12,74$ \\
Depósito de gás & 60,02 & 52,45 & 14,43 \\
Distribuição & 752,42 & 661,46 & 13,75 \\
Refeitório & 1,84 & 1,36 & 35,29 \\
DML & 12,88 & 21,11 & $-38,99$ \\
Sanitário feminino & 10,33 & 31,06 & $-66,74$ \\
Sanitário masculino & 9,1 & 9,08 & 0,22 \\
Sala do nutricionista & 10,67 & 10,67 & 0,00 \\
Administração & 11,88 & 11,88 & 0,00 \\
Almoxarifado & & & \\
\hline
\end{tabular}

Legenda: DML = Depósito de Material de Limpeza. Fonte: Autoria própria.

Quanto ao fluxo dos alimentos, na Unidade em estudo apresentava-se com cruzamentos favorecendo o risco sanitário e comprometimento da qualidade nutricional. O fluxo das carnes, por exemplo, apresentou inadequações sob o ponto de vista higiênico-sanitário previsto nas legislações e recomendações acerca de Boas Práticas de Fabricação, sendo que o ponto crítico era a etapa de descongelamento das carnes que não ocorria em temperatura ideal devido à falta de espaço nas câmaras refrigeradas (Figura 3). Neste caso, a inadequação nesta etapa relacionava-se diretamente com falha na estrutura física adequada às operações necessárias, já que se estivesse previsto o espaço de armazenamento refrigerado compatível com as atividades realizadas, não haveria necessidade de descongelar carnes no açougue sem a adoção das recomendações higiênico- 
sanitária.

Figura 3 - Fluxo das carnes na Unidade de Alimentação e Nutrição em estudo. Salvador, Bahia, 2015.

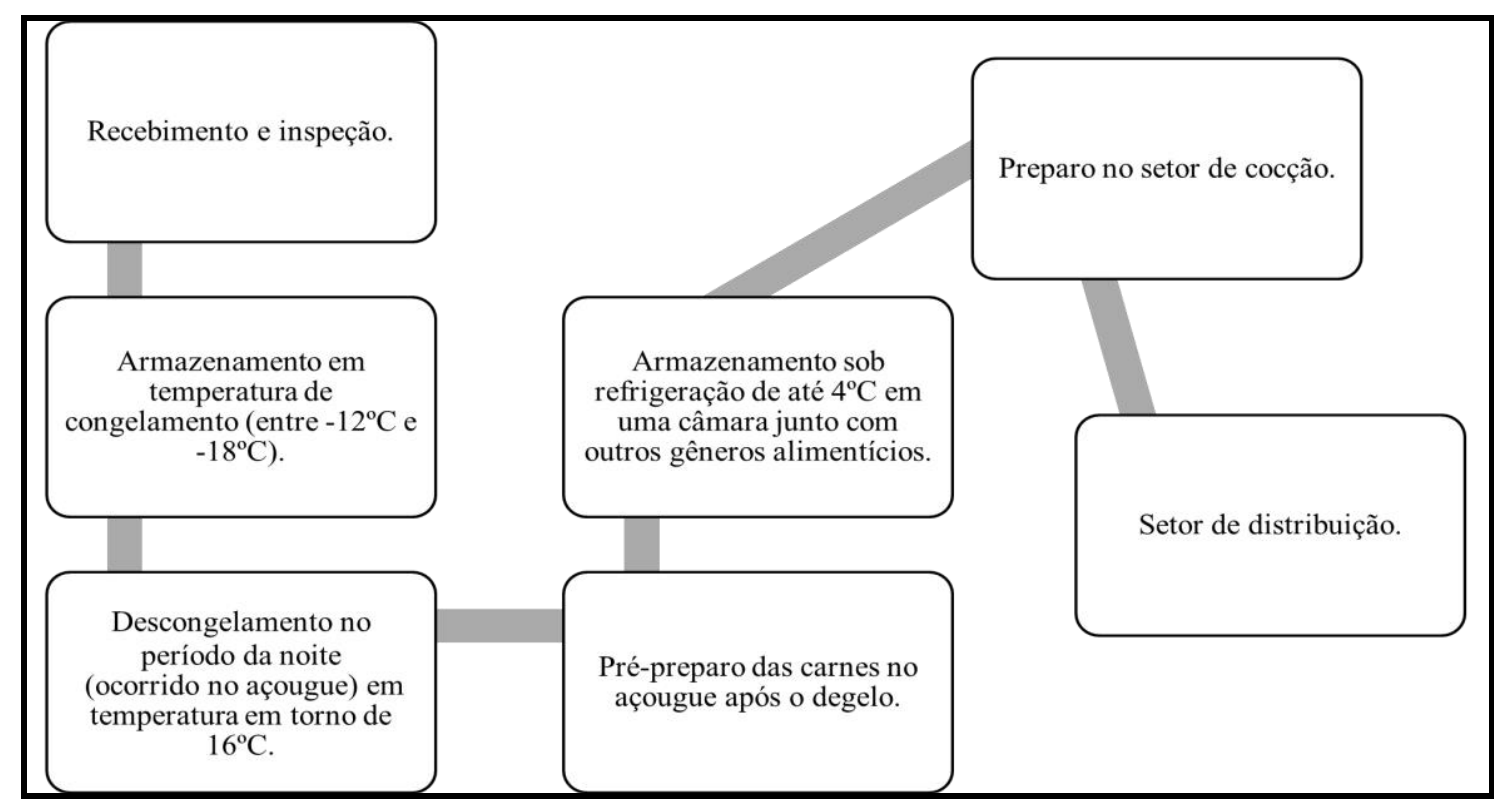

Fonte: Autoria própria.

Em layout de indústria de alimentos analisado por Sant'Ana (2012), o fluxo de carnes deve ser linear com o objetivo de evitar cruzamento de fluxo e as distâncias devem ser encurtadas, assim como o trânsito do alimento na Unidade e a possível perda de temperatura e contaminação cruzada.

Os espaços subdimensionados dedicados ao armazenamento de gêneros se constituem como fator crítico para garantia da qualidade higiênico-sanitária dos alimentos, devendo ser dimensionados adequadamente a fim de garantir proteção contra contaminação e reduzir a deterioração ou perda de qualidade nutricional. A falta de espaço nas câmaras frias impedia o armazenamento correto dos gêneros e por isso parte destes era estocada fora da temperatura correta e em locais inapropriados, gerando risco de contaminação e perda dos produtos pelas más condições de armazenamento. Além disso, os gêneros que eram armazenados nas câmaras, não estavam em condições ideais, pois para aproveitar ao máximo os espaços, não eram respeitadas as separações necessárias entre os estrados para circulação do ar e garantia de que todos os alimentos estavam atingindo a temperatura correta (Brasil, 1997).

Assim, com proposta de aumento das áreas de armazenamento os problemas identificados serão solucionados, além de poder favorecer menor periodicidade de entregas, gerando maiores possibilidades de negociação de preços. $\mathrm{O}$ melhor acondicionamento de gêneros também está diretamente ligado a menor perda de produtos que se deterioram em temperaturas inadequadas. Também, foram criadas câmaras exclusivas para cada tipo de gênero o que facilita a manutenção de temperatura adequada e evita contaminação cruzada. Todas estas medidas geram, por consequência, economia de recursos financeiros, justificando o investimento em reforma (Teixeira et al., 1990). Assim, como proposta, o fluxo das carnes seguirá do recebimento e inspeção até a câmara de congelados. Posteriormente, para a de refrigeração onde ocorrerá o descongelamento. A etapa de pré-preparo ocorrerá no açougue, onde a carne será porcionada e condimentada e poderá então seguir para a cocção ou retornar ao resfriamento para aguardar preparação em uma câmara específica.

$\mathrm{Na}$ UAN, outro fluxo que se mostrou problemático foi o dos vegetais (Figura 4), onde os problemas eram em decorrência da falta de espaço suficiente para armazenamento e pré-preparo correto dos gêneros, devido ao dimensionamento inadequado dos setores (setor de recebimento e inspeção maior do que o necessário; setores de armazenamento e pré-preparo 
subdimensionados). Segundo a ABERC (2009), os hortifrútis devem ser armazenados em temperatura de refrigeração (até $10^{\circ} \mathrm{C}$ ), para garantir a manutenção de suas características e evitar a deterioração dos mesmos, afinal o armazenamento é uma etapa de controle de qualidade e, portanto, a matéria-prima deve estar protegida de qualquer tipo de contaminação.

$\mathrm{Na}$ proposta de novo layout, os vegetais serão recebidos e inspecionados em área adequada e deverão passar por processo de pré-higienização para remoção de sujidades. Então serão armazenados na câmara refrigerada ou serão encaminhados para a câmara de maturação, onde poderão permanecer protegidos até atingirem o ponto de maturação desejado para consumo. Posteriormente, os vegetais pré-higienizados serão encaminhados para o setor de pré-preparo de saladas cruas ou cozidas e então diretamente para a distribuição através do pass-through localizado no próprio setor.

Figura 4 - Fluxo dos vegetais na Unidade de Alimentação e Nutrição em estudo. Salvador, Bahia, 2015.

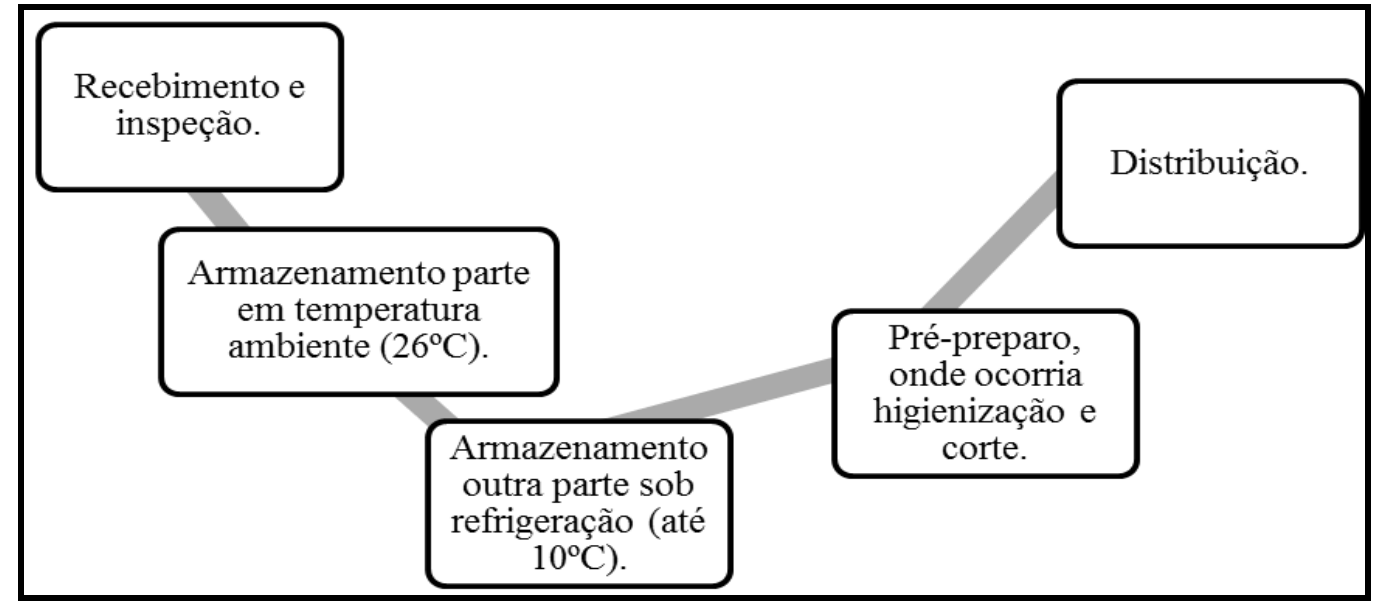

Fonte: Autoria própria.

O setor de pré-preparo de vegetais deve ser destinado à seleção, higienização, descascamento, cortes, acabamentos e montagem dos vegetais, porém na Unidade, a área ainda era utilizada para o processo de pré-higienização, já que não havia outro espaço. Logo, era mais uma prática que punha em risco a segurança dos alimentos, tendo em vista que na Unidade eram produzidas saladas cruas, portanto não passavam por processamento térmico que pudesse eliminar possível contaminação ${ }^{4}$. Uma alimentação variada e nutricionalmente equilibrada é também determinada pelas condições estruturais de uma UAN e a falta de espaços adequados pode incorrer em monotonia alimentar e prejuízo à saúde dos comensais (Sant'Ana, 2012). Com a proposta de novo layout, a área foi dividida entre área para salada crua e cozida e assim ampliar a variação deste prato sem ocorrência de cruzamento de fluxos dos vegetais crus, higienizados e dos prontos para consumo. Como na UAN em estudo não havia oferta de salada cozida por conta da insuficiente estrutura física, este foi um fator imprescindível a ser considerado no projeto proposto.

A matéria prima direcionada para o estoque seco iniciava o seu fluxo no recebimento e inspeção; passando diretamente para o estoque. Posteriormente os gêneros eram separados para o estoque diário e por fim seguiam para o preparo. Portanto, um fluxo que atendia ao sugerido pela literatura, apesar da Unidade não possuir área destinada à catação de grãos, o que fazia com que estes alimentos fossem selecionados em uma bancada de apoio na área de cocção. No estoque, os insumos eram armazenados em temperatura ambiente, organizados sob estrados ou em prateleiras, separados por categoria e de acordo com a data de fabricação. Como proposta no novo layout, na pós-inspeção, os gêneros secos serão armazenados na despensa e posteriormente serão utilizados nos diversos setores conforme solicitação. Foi projetado um espaço mais adequado e reservado para o estoque diário.

As polpas de frutas, laticínios e ovos seguiam do recebimento para as câmaras correspondentes, de lá seguiam para 
uso nos setores de preparo. Os materiais descartáveis eram recebidos no setor de recepção e encaminhados diretamente ao almoxarifado no piso superior da UAN. Já os produtos de limpeza eram recebidos e armazenados no depósito adequado que se localizava ao lado da recepção. Na proposta de layout, estes fluxos não foram alterados.

Dentre os setores de pré-preparo, os que se apresentaram mais críticos foram os de pré-preparo de sobremesas, patissaria e opção ovolactovegetariana. Desta forma, a ampliação destas áreas foi pensada para que fosse possível o retorno de suas atividades originais que compreendiam as preparações mais elaboradas e corte de frutas, e que foram proibidas pela vigilância sanitária por falta de infraestrutura condizente.

Em relação ao setor de cocção, o espaço era menor do que o sugerido pela literatura, o que fazia com que os equipamentos e manipuladores estivessem concentrados em um espaço insuficiente, facilitando a concentração de calor e consequentemente gerando desconforto térmico e risco de acidentes de trabalho (Brasil, 1978 a,b,c; Sant'Ana, 2012).

O fluxo de resíduos apresentou inadequação na medida em que o lixo passava por dentro de toda a Unidade até chegar à área externa e, por ser retirado com frequência, muitas vezes o lixo era removido em momentos em que havia produção das refeições. Portanto, tal fluxo poderia gerar contaminação dos alimentos preparados. Como proposta, o fluxo dos resíduos foi alterado para que o lixo pudesse ser retirado diretamente para fora nos setores de pré-preparo de saladas e de lavagem de bandejas. Sendo assim, os resíduos não passariam pelo interior da UAN e serão armazenados diretamente na câmara de lixo localizada na área externa da Unidade.

Com áreas subdimensionadas, os sanitários e vestiários dos manipuladores de alimentos estiveram em desacordo com a legislação brasileira (Brasil, 1978 ${ }^{\mathrm{d}, \mathrm{e}}$ ), que prevê os espaços mínimos exigidos para garantia de conforto nos locais de trabalho. Os manipuladores adentravam na UAN pela porta ao lado do setor de recebimento e se direcionavam para o pavimento superior onde se localizavam os vestiários, passando, portanto pela área de produção; guardavam os pertences e desciam para o pavimento térreo onde trocavam de roupa e faziam a higiene pessoal nos sanitários. Então, retornavam ao vestiário para guardar as roupas e seguiam para suas áreas de trabalho.

Portanto, tal fluxo estava inadequado, como a ausência de entrada oportuna para os manipuladores, já que os mesmos chegavam da rua, ainda com as suas roupas e sapatos comuns, não sendo interessante que percorressem o interior da Unidade com tais vestimentas. A presença dos armários no andar superior e o sanitário, que também era utilizado como vestiário, no piso térreo não favorecia o fluxo de pessoal criando deslocamentos excessivos e desnecessários. Outro problema relacionado a este fluxo era a localização do sanitário que tinha conexão direta com a área de produção, sendo uma falha crítica de acordo com a legislação sanitária vigente (Brasil, 2004).

Com tais constatações, as instalações sanitárias e vestiários propostos para os manipuladores passaram a atender às referências e legislações que orientam o bom estado de conservação, entrada independente e sinalizam que a conexão entre estes espaços e a área de produção devem possuir barreiras que imponham mais segurança aos produtos alimentícios (Brasil, 2002; Brasil, 2004). Na proposta, os manipuladores terão uma entrada independente, passando diretamente para os vestiários e sanitários separados por sexo. Depois de realizada a higiene pessoal e vestimenta do fardamento, os manipuladores seguirão à suas áreas de trabalho. Na saída desta área, propõe-se um ponto de higienização das mãos e botas. O sanitário exclusivo dos manipuladores passará a ter duas barreiras até a área de preparo, pois serão previstas portas de acesso a cada sanitário, feminino e masculino, e também uma porta do tipo "vai-e-vem" separando a área de circulação dos sanitários e o ponto de higienização das mãos e botas.

No que tange o fluxo dos comensais, os mesmos entravam no refeitório e se direcionavam ao caixa para aquisição das fichas. Posteriormente, passavam pelas ilhas de lavagem das mãos e seguiam para os balcões de distribuição onde formavam duas filas e saíam todos pelo mesmo local, onde havia uma catraca e se direcionavam para as mesas. O fluxo de comensais proposto se inicia da portaria projetada para recebê-los em duas filas (uma para alunos bolsistas e outra para os pagantes). 
Após a compra do ticket, os comensais serão direcionados às ilhas de lavagem de mãos e posteriormente para os balcões de distribuição. Depois de realizada a refeição, o comensal devolverá sua bandeja estampada e talheres no lado esquerdo e se dirigirá à saída. As instalações sanitárias separadas por sexo previstas para este público não serão alteradas.

No projeto proposto, áreas que não existiam, como o setor de catação de grãos, câmara de maturação de vegetais, montagem de refeições transportadas, área para guarda de panelas e utensílios limpos e sala de descanso para os manipuladores, passaram a existir (Figura 2). Os espaços planejados para a área de lavagem de bandejas e área de lavagem de utensílios e panelas cria um fluxo mais adequado e que minimiza o contato de objetos sujos com os já higienizados, na medida em que divide a entrada de material sujo e a saída dos higienizados por barreiras físicas, assim como orienta a ABERC (2009). Esta medida objetiva minimizar a contaminação por resíduos e facilitar a guarda dos materiais sem o risco de contaminação por produtos de limpeza ou restos de alimentos.

Para a modalidade de refeições transportadas, que não possuía área específica para a etapa de montagem, a área projetada para tal ação é extremamente importante, pois, as refeições eram montadas em bancadas de apoio na área de cocção, além de serem pesadas e conferidas em local inadequado, com grande circulação de pessoas e que, por vezes, dos resíduos da produção. Vale ressaltar que a expedição das refeições transportadas deve ser feita de maneira a proteger o produto e evitar contato com contaminantes (Brasil, 2004).

Do ponto de vista higiênico-sanitário, o layout proposto para a UAN consegue minimizar os cruzamentos de fluxo e evitar a contaminação cruzada se adequando de maneira eficiente à produção de alimentos seguros e com melhor qualidade nutricional. Também se tornam relevantes essas alterações, uma vez que são considerados fatores como segurança e conforto para os manipuladores, prevenindo acidentes de trabalho e aumentando a produtividade.

\section{Considerações Finais}

O planejamento físico adequado e respaldado no reconhecimento das características da produção de cada Unidade de Alimentação e Nutrição é um fator imprescindível para a qualidade da produção de alimentos e pode evitar interrupções e cruzamentos do fluxo de produção e contaminação cruzada. Portanto, o planejamento físico interfere no cumprimento das Boas Práticas de Fabricação e na adequação às legislações sanitárias vigentes no país. É imprescindível a compreensão de todos os fatores que devem ser considerados para que o planejamento seja eficiente e atenda às demandas de cada Unidade, evitando situações que coloquem em risco a segurança das refeições produzidas. Do mesmo modo, o dimensionamento dos setores deve ser adequado à realidade de produção e baseado em critérios específicos e em dados da literatura que servem como balizadores para tomada de decisões mais assertivas.

A Unidade de Alimentação e Nutrição em estudo apresentou diversas inadequações em relação às Boas Práticas de Fabricação que podem levar a riscos sanitários. O dimensionamento físico e os fluxos de produção da Unidade se relacionam diretamente a este fator, uma vez que muitas inadequações encontradas poderiam ser corrigidas se houvessem espaços suficientes e melhor distribuídos. Neste sentido, o projeto proposto soluciona aspectos relevantes acerca do dimensionamento e fluxo de produção, devendo ser revista a capacidade máxima de produção a fim de adequá-la à realidade da Unidade.

Como sugestão para trabalhos futuros, a análise das condições físico-funcionais de outros restaurantes universitários no país é de extrema importância, a fim de obter-se um mapeamento das condições em que estes serviços de alimentação estão produzindo refeições para a comunidade universitária e assim auxiliar o planejamento de cardápios, dado que para alcance dos objetivos com a oferta de refeições aos estudantes, em atendimento ao Programa Nacional de Assistência Estudantil, um bom cardápio deve ser executado e para isso, as condições de estrutura física adequadas são necessárias. 
Research, Society and Development, v. 11, n. 3, e46111326844, 2022

(CC BY 4.0) | ISSN 2525-3409 | DOI: http://dx.doi.org/10.33448/rsd-v11i3.26844

\section{Agradecimentos}

Agradecemos ao arquiteto pela elaboração da Planta Baixa.

\section{Referências}

Associação Brasileira das Empresas de Refeições Coletivas - ABERC (2009). Manual ABERC de práticas de elaboração e serviço de refeições para coletividades. (9a ed.).

Alonso, C. M. P. et al. (2015). Capacitação de Manipuladores de Alimentos: Um estudo de caso em um restaurante universitário. Revista Higiene Alimentar, 29.

Bernardo, P. V. et al. (2014). Avaliação das boas práticas na produção de refeições na rede hoteleira de Belo Horizonte, MG. Cient. Ciênc. Biol. Saúde. 16(4): 265-270.

Brasil (a). (1978). Norma Regulamentadora - NR nº7. Programa de controle médico de saúde ocupacional. Portaria GM nº3.214, de 08 de junho de 1978. Ministério do Trabalho. Diário Oficial da União.

Brasil (b). (1978). Norma Regulamentadora - NR n9. Programa de prevenção de riscos ambientais. Portaria GM n³.214, de 08 de junho de 1978. Ministério do Trabalho. Diário Oficial da União.

Brasil (c). (1978). Norma Regulamentadora - NR n¹7. Ergonomia. Portaria GM n³.214, de 08 de junho de 1978. Ministério do Trabalho. Diário Oficial da União.

Brasil (d). (1978). Portaria 3.214 de 08 de junho de 1978. Aprova as Normas Regulamentadoras do Capítulo V, Título II, da Consolidação das Leis do Trabalho (CLT), relativas à segurança e Medicina do Trabalho. Ministério do Trabalho. Diário Oficial da União.

Brasil (e). (1978). Norma Regulamentadora - NR n²4. Condições sanitárias e de conforto nos locais de trabalho. Ministério do Trabalho. Diário Oficial da União.

Brasil. (1997). Portaria n³26 de 30 de julho de 1997. Regulamento técnico sobre as condições higiênico-sanitárias e de boas práticas de fabricação para estabelecimentos produtores/industrializadores de alimentos. Ministério da Saúde. Diário Oficial da União.

Brasil. (2002). Resolução da Diretoria Colegiada - RDC n²75 de 21 de outubro de 2002. Dispõe sobre o regulamento técnico de procedimentos operacionais padronizados aplicados aos estabelecimentos produtores/industrializadores de alimentos e a lista de verificação das boas práticas de fabricação em estabelecimentos produtores/industrializadores de alimentos. Agência Nacional de Vigilância Sanitária. Diário Oficial da União.

Brasil. (2004). Resolução da Diretoria Colegiada RDC n²16 de 15 de setembro de 2004. Dispõe sobre Regulamento Técnico de Boas Práticas para Serviços de Alimentação. Agência Nacional de Vigilância Sanitária. Diário Oficial da União.

Cardoso, R. C. V. et al. (2010). Programa nacional de alimentação escolar: há segurança na produção de alimentos em escolas de Salvador (Bahia)?. Rev. Nutr. Campinas, 23(5):801-811.

Conselho Federal de Nutrição. (2018). Resolução do Conselho Federal de Nutricionistas - CFN nº600 de 25 de fevereiro de 2018 . Dispõe sobre a definição das áreas de atuação do nutricionista e suas atribuições, indica parâmetros numéricos mínimos de referência, por área de atuação, para a efetividade dos serviços prestados à sociedade e dá outras providências. Disponível em: http://resolucao.cfn.org.br/

Correia, M. J. F. S., \& Rocha, A. M. C. N. (2012). A importância dos fatores estruturais na garantia da segurança alimentar na produção de refeições para escolares. Demetra., 7(1); 39-46.

Food and Agriculture Organization of the United Nations. (1993). Codex Alimentarius. Code of Hygienic Practice for Precooked and Cooked Foods in Mass Catering. http://www.codexalimentarius.net/web/standard_list.jsp

Ferreira, M. A. et al. (2011). Avaliação de adequação às boas práticas em unidades de alimentação e nutrição. Rev. Inst. Adolfo Lutz., 70(2):230-235.

Vozes. http://www.adm.ufrpe.br/sites/ww4.deinfo.ufrpe.br/files/Fundamentos_de_Metodologia_Cienti\%CC\%81fica.pdf

Leal, J. P. N., et al. (2019). Avaliação das condições ambientais do restaurante escola de uma universidade pública de Pelotas - RS. RASBRAN - Revista da Associação Brasileira de Nutrição. 10(1):103-108.

Mezomo, I. F. B. (1994). A administração de serviços de alimentação. (4a ed.), Terra.

Sant'Ana, H. M. P. (2012). Planejamento físico-funcional de unidades de alimentação e nutrição. Rubio.

São José, J. F. B., Coelho, A. I. M., \& Ferreira, K. R. (2011). Avaliação das boas práticas em unidade de alimentação e nutrição no município de ContagemMG. Alim. Nutr. Araraquara, 22(3): 479-487.

Silva Filho, A. R. A. (1996). Manual básico para planejamento e projeto de restaurantes e cozinhas industriais. Varela.

Silva, A. L., \& Rentes, A. F. (2012). Um modelo de projeto de layout para ambientes job shop com alta variedade de peças baseado nos conceitos da produção enxuta. São Carlos: Gest. Prod.,19(3); 531-541.

Silva Júnior, E. A. (2014). Manual de controle higiênico-sanitário em serviços de alimentação. (7a ed.), Varela. 
Research, Society and Development, v. 11, n. 3, e46111326844, 2022

(CC BY 4.0) | ISSN 2525-3409 | DOI: http://dx.doi.org/10.33448/rsd-v11i3.26844

Susin, V., et al. (2017). Condições higiênico-sanitárias, estruturais e de funcionamento de Unidades de Alimentação e Nutrição. Vigil. sanit. Debate, 5(1):6068. https://doi.org/10.22239/2317-269x.00820

Teixeira, S. M. F. et al. (1990). Administração aplicada às unidades de alimentação e nutrição. Atheneu.

Teixeira, S. M. F. G. et al. (1992). Índices para cálculos de unidades de alimentação e nutrição (UAN). Alimentos e Nutrição. 